\title{
QUEEN'S
UNIVERSITY
BELFAST
}

\section{Development and evaluation of calcium hydroxide-coated, pericardium-based biomembranes for direct pulp capping}

Klein-Júnior, C. A., Reston, E., Plepis, A. M., Martins, V. C., Pötter , I. C., Lundy, F., Hentschke , G. S.,

Hentschke, V. S., \& El Karim, I. (2019). Development and evaluation of calcium hydroxide-coated, pericardiumbased biomembranes for direct pulp capping. Journal of Investigative Clinical Dentistry, 10(1), [e12380]. https://doi.org/10.1111/jicd.12380

Published in:

Journal of Investigative Clinical Dentistry

Document Version:

Peer reviewed version

Queen's University Belfast - Research Portal:

Link to publication record in Queen's University Belfast Research Portal

Publisher rights

() 2018 John Wiley \& Sons Australia, Ltd.

This work is made available online in accordance with the publisher's policies. Please refer to any applicable terms of use of the publisher.

\section{General rights}

Copyright for the publications made accessible via the Queen's University Belfast Research Portal is retained by the author(s) and / or other copyright owners and it is a condition of accessing these publications that users recognise and abide by the legal requirements associated with these rights.

Take down policy

The Research Portal is Queen's institutional repository that provides access to Queen's research output. Every effort has been made to ensure that content in the Research Portal does not infringe any person's rights, or applicable UK laws. If you discover content in the Research Portal that you believe breaches copyright or violates any law, please contact openaccess@qub.ac.uk. 


\title{
Development and evaluation of calcium hydroxide-coated, pericardium-based biomembranes for direct pulp capping
}

\author{
Celso A. Klein-Júnior ${ }^{1}$ | Eduardo Reston ${ }^{1}$ | Ana M. Plepis ${ }^{2}$ | Virginia C. Martins ${ }^{2}$ | \\ Isabel C. Pötter ${ }^{1}$ | Fionnuala Lundy ${ }^{3}$ | GuilhermeS. Hentschke ${ }^{1}$ Vítor S. Hentschke ${ }^{1}$ | \\ Ikhlas El Karim ${ }^{3}$
}

\author{
${ }^{1}$ Department of Operative Dentistry, \\ Lutheran University of Brazil, Cachoeira do \\ Sul, Brazil \\ ${ }^{2}$ Department of Biomaterials, State \\ University of São Paulo, São Paulo, Brazil \\ ${ }^{3}$ Centre for Experimental Medicine, Queen's \\ University Belfast, Belfast, UK

\section{Correspondence} \\ Dr Guilherme S. Hentschke, Department of \\ Operative Dentistry, Lutheran University of \\ Brazil, Cachoeira do Sul, Brazil. \\ Email: guilherme.scotta@gmail.com
}

\begin{abstract}
Aim: The aim of the present study was to develop a bovine pericardium biomembrane (BPB) and to evaluate pulp response in vivo.

Methods: A double-layer bovine BPB/chitosan was manufactured, and the porous chitosan side was coated with calcium hydroxide. The microstructure of the matrices was evaluated with electron microscopy. To test pulp response, cavities were prepared on the occlusal surface of Wistar rats' mandibular left first molars and capped with matrices, followed by appropriate adhesives/composite restorations. The animals were divided into three groups: group 1, calcium hydroxide alone; group 2, BPB without calcium hydroxide; and group 3, BPB coated with calcium hydroxide. Specimens were processed and histologically evaluated at 7, 14, and 30 days, postoperatively.

Results: Electron microscopy showed porous chitosan surface and a cohesive calcium hydroxide layer. Histological analysis showed that groups 1 and 3 had mild odontoblast layer disorganization, but normal pulp tissue appearance at 7, 14, and 30 days. At the same time points, group 2 showed a loss of general pulp tissue, pulp necrosis, and periapical abscess in some teeth.

Conclusion: Coated bovine pericardium-based biomembranes resulted in favorable outcomes in cases of pulp exposure after a 30-day observation period, and might protect against injuries caused by adhesive systems and composites.

KE Y WO R D S

biocompatible material, bovine pericardium biomembrane, calcium hydroxide, dental pulp, pulp capping
\end{abstract}

\section{1 | INTRODUCTION}

Exposure of the dental pulp due to iatrogenic or pathological causes is a common but challenging dental problem to treat successfully. Calcium hydroxide is widely used and has been the material of choice for the treatment of exposed dental pulp in direct pulp capping procedures. ${ }^{1}$ It is recognized as a gold standard material for pulp capping, as it possesses many properties, including anti-inflammatory, antimicrobial, and most importantly, the ability to induce reparative dentine formation. ${ }^{2}$ Calcium hydroxide is known to induce reparative dentine formation via different mechanisms, including a direct ef- fect on recruitment and differentiation of dental pulp stem cells into odontoblast-like cells. ${ }^{3}$ Calcium hydroxide has also been shown to induce its effect indirectly via the release of growth factors from 
dentine to facilitate tertiary dentinogenesis. ${ }^{4}$ The material, however, is not without limitations, and the lack of appropriate seal around the exposure site, together with poor mechanical properties, has led to the development of alternatives, such as calcium silicate cement biomaterials, including mineral trioxide aggregate and Biodentine. Calcium silicate cements have been reported to demonstrate better mechanical properties and produce better quality reparative den- tine than calcium hydroxide. ${ }^{5}$ Calcium silicate cements show good quality in long-term analyses; for example, long-term higher frac- ture resistance at 24 months and resistance to dislodgement from dentin when immersed in phosphate-buffered saline.6,7 These ce- ments induce reparative dentine formation via the release of cal- cium hydroxide upon hydration, ${ }^{8}$ but unlike calcium hydroxide-alone preparations, long-term clinical data on the performance of these materials are not yet available. Furthermore, limitations, such as tooth discoloration and the presence of heavy metal ions that might impact the biologic properties of calcium silicate cements in vivo, have been reported. ${ }^{9}$

In addition to biocompatibility and ability to induce dentine formation, an ideal pulp capping material should also adhere firmly to the dentine to provide a tight seal against bacterial invasion and diffusion of chemicals released by restorative materials. To allow for normal pulp tissue development, the pulp capping material should also act as a matrix to mechanically support and allow pulp cells to adhere and proliferate. These properties, however, can only be provided by biologic matrices and biomembranes, and not by calcium hydroxide or calcium silicate cements alone. Emerging studies have shown improved pulp capping outcomes when growth factors were applied with biomembranes. ${ }^{10}$ Therefore, the idea of using calcium hydroxide-coated biomembranes might enhance its applicability for direct pulp capping and improve treatment outcomes in vital pulp therapy.

Bovine pericardium is a biomembrane source that has been used as a cell scaffold in tissue engineering. ${ }^{11}$ Bovine pericardium can be reticulated in the laboratory to become a biomaterial with mild inflammatory and immune responses, improved biocompatibility, improved mechanical response, and ability to promote cell growth. ${ }^{12}$ To date, the use of the pericardium membrane as A scaffold for di- rect pulp capping has not be explored.

The objectives of the present study were to develop and characterize bovine pericardium-based biomembranes to be used for pulp capping and to evaluate pulpal responses to these matrices in the presence and absence of calcium hydroxide in an animal model.

\section{2 | MATERIAL S AND METHODS}

\section{1 | Bovine pericardium biomembrane preparation}

Bovine pericardium biomembrane (BPB) was produced at São Carlos Institute of Chemistry, University of São Paulo (São Paulo, Brazil). Bovine pericardium specimens were obtained from slaughterhouses. The specimens were mechanically cleaned and washed alternately with distilled water and .9\% sodium chloride solution. Once cleaned, bovine pericardium tissue was immersed in an alkaline solution $\mathrm{pH}$ 13) for 24 hours, using a protocol developed in previous studies. ${ }^{13}$ In short, the bovine pericardium was treated at $25^{\circ} \mathrm{C}$ with an alkaline solution ( $3 \mathrm{~mL} \mathrm{~g}^{-1}$ of tissue) containing salts (chlorides and sulfates) of alkaline $\left(\mathrm{K}^{+}\right.$and $\left.\mathrm{Na}^{+}\right)$and alkaline earth $\left(\mathrm{Ca}^{2+}\right)$ metals. The material was washed with $3 \%$ boric acid solution, deionized water, $0.3 \%$ ethylenediaminetetraacetic acid (EDTA), and then again with deionized water. Subsequently, samples were rinsed in sodium phosphate buffer $\mathrm{pH} 7.4$ for 24 hours, and then washed again with deionized water, frozen, and lyophilized.

\section{2 | Preparation of bovine pericardium biomembrane/chitosan matrices}

To make double-layer matrices, the prepared BPB membrane was covered with a solution containing chitosan and pig skin gelatin.

Chitosan was obtained from Loligo spp. squid pens (gladii) and was prepared in three steps, as previously described: ${ }^{14}$ (a) gladii were washed, dried in an incubator at $40^{\circ} \mathrm{C}$, ground, demineralized, and deproteinized through alkaline treatment with $0.3 \mathrm{~mol} \mathrm{~L}^{-1}$ sodium hydroxide ( $\mathrm{NaOH}$ ) to obtain $\beta$-chitin; (b) subsequently, deacetylation was achieved with $40 \% \mathrm{NaOH}$, to obtain chitosan; and (c) chitosan gel $(1 \%)$ was prepared by dissolving chitosan in $1 \%$ acetic acid with constant stirring for 24 hours at room temperature. Gelatin gel (Sigma-Aldrich, St Louis, MO) obtained from pig skin was dissolved in water and gelatinized at $60^{\circ} \mathrm{C}$ for 30 minutes at $1 \%$ concentration. Matrices were prepared as follows: $1 \mathrm{~g}$ chitosan gel was placed in a Teflon mold and frozen with liquid nitrogen. The bovine pericardium hydrated in deionized water was then placed on top of the chitosan gel, and the matrix was frozen again. These materials were lyophilized to obtain samples consisting of chitosan sponge on one side and bovine pericardium matrix on the other.

\section{3 | Calcium hydroxide coating of the matrices}

In half of the matrices prepared, the side containing the chitosan sponge was coated with calcium hydroxide. Calcium hydroxide solution prepared with $0.1 \mathrm{~g}$ calcium hydroxide and $0.9 \mathrm{~g}$ of gelatin $1 \%$ was added to the chitosan side of the membrane, and the ma- trices were subjected to forced-air drying at room temperature and ethylene oxide sterilization. Forced-air drying is required to cause sponge compaction and hydroxide adhesion. The morphology and microstructure of the prepared membranes were then examined with scanning electron microscopy (SEM). Membranes were placed onto an electric-adhesive film and sputter-coated with gold and ex- amined by SEM (JSM 6060; Jeol, Peabody, MA). Thermal changes were evaluated with differential scanning calorimetry (DSC 2010; TA Instruments, New Castle, DE).

\section{4 | Animals}

The animal model was selected based on the pulp capping protocol for the evaluation of new dental materials prior to use in humans. 
The study was approved by the animal experimentation ethics committee of the institution (protocol no. 2012-13P). Forty-five nondecayed mandibular left first molars of healthy 8-week-old male Wistar rats (Rattus Norvegicus), weighing 250-300 g each, were used in the present study. The rats were randomly divided into three groups of 15 animals each to receive one of the following pulp capping agents: group 1, calcium hydroxide alone; group 2, BPB with no calcium hydroxide coating; and group 3, BPB with calcium hydroxide coating.

The rats were anesthetized with ketamine $10 \%(0.1 \mathrm{~mL} / 100 \mathrm{~g}$ body weight) (Cetamin; Syntec, São Paulo, SP, Brazil) and xylazine $10 \%$ (Anasedan; Vetbrands, São Paulo, Brazil) injected intramuscularly at a 2:1 ketamine : xylazine (v/v) ratio. Cavities were prepared with a 1/4-inch bur (Dentsply Maillefer, Ballaigues, Switzerland) under water cooling on the occlusal surface of the mandibular left first molar of each animal. This procedure was performed under rubber dam isolation. In order to expose the pulp chamber, a final perforation was carefully made with a steel probe, and the area gently cleaned with sterile cotton swabs and distilled water. The teeth were then restored according to the relevant group assignment. For the calcium hydroxide-only group, cavities were treated for 5 minutes with Ostoporin (Farmoquímica, Rio de Janeiro, Brazil), followed by application of calcium hydroxide pro-analysis powder, calcium hydroxide cement (Dycal; Dentsply Caulk, Milford, DE), glass ionomer (Vidrion R; SS White, Rio de Janeiro, Brazil), self-etch adhesive (Adper Easy One; 3M/ESPE, St Paul, MN), and compos- ite resin (Filtek Z250; 3M/ESPE). The biomembrane experimental groups received Otosporin, followed by the application of the matrices, and the cavities were then restored with self-etch adhesive and composite resin.

\section{5 | Histological analysis}

Five rats from each group were killed at 7, 14, and 30 days, postoperatively, with an overdose of sodium pentobarbital $5 \%\left(40 \mathrm{mg} \mathrm{kg}^{-1}\right.$ body weight) (Sigma-Aldrich), injected intraperitoneally after each observation period. The left half of the mandible containing the experimental tooth was carefully dissected using a scalpel and fixed in $4 \%$ phosphate-buffered paraformaldehyde solution at $4^{\circ} \mathrm{C}$ for 24 hours. The specimens were decalcified in $10 \%$ EDTA-2Na ( $\mathrm{pH} \mathrm{7.4)} \mathrm{at} \mathrm{room}$ temperature for 4 weeks. Subsequently, the specimens were dehydrated in an ascending ethanol series, dealcoholized in xylene, and then embedded in paraffin. Serial $5-\mu \mathrm{m}$ sections were cut and stained with hematoxylin-eosin. The slides were examined under a light microscope at $\times 200$ magnification (AxioSkop 40; Carl Zeiss, Goettingen, Germany) by a single observer who was blinded to the group assignment. The stained sections were evaluated for histological changes, and a score of 1-4 was assigned considering the parameters described later. ${ }^{15}$

\section{6 | Pulp tissue disorganization}

Pulp tissue disorganization was as follows:

(1). normal or almost normal tissue morphology (none);
(2). odontoblast layer disorganization, but the deep part of pulp is normal (mild);

(3). loss of general tissue morphology (moderate);

(4). necrosis in the coronal third or more of the pulp (severe)

\section{7 | Inflammatory cell infiltration}

Inflammatory cell infiltration was as follows:

(1). absence or presence of a few scattered inflammatory cells in the pulp (none);

(2). mild acute/chronic cell lesion (mild);

(3). moderate inflammatory cell lesions (moderate inflammatory infiltrate) seen as an abscess or densely-stained infiltrates of polymorphonuclear leukocytes and lymphocytes in the coronal third or more of the pulp and/or the mid-pulp (moderate);

(4). pulp necrosis due to a severe degree of infection or lack of tissue in half or more of the pulp (severe)

\section{8 | Statisticalanalysis}

Data on pulp tissue disorganization and inflammatory cell infiltration after pulp capping obtained at 7, 14, and 30 days were statistically analyzed using the Kruskal-Wallis test, followed by Student-NewmanKeuls test for the contrast analysis between groups. The level of significance was set at $5 \%$.

\section{3 | RESULTS}

\section{1 | Characterization of the matrices}

The microstructure of the matrices was evaluated by SEM. As shown in Figure 1 , the bovine pericardium side after alkaline hydrolysis revealed a compact structure with the presence of fibers, while the chitosan side showed a porous matrix. In cross-section, the matrix revealed a spongy side with interconnected channels and the lay- ers that make up the bovine pericardium. The addition of the gelatin gel containing calcium hydroxide on the chitosan sponge formed an adherent layer (Figure 1D,E). The differential scaning calorimetry (DSC) analysis to test the stability and degradation potential showed that the addition of calcium hydroxide and chitosan was associated with reduced thermal stability, and therefore, more degradation compared to a pure pericardium membrane (Figure 1F).

\section{2 | Histological findings}

The results of the analysis of pulp tissue disorganization and inflammatory cell infiltration are shown in Tables 1 and 2. Groups 1 and 3 showed mild odontoblast layer disorganization, but with normal pulp tissue appearance, and slight infiltration of a few scattered inflammatory cells in the pulp at 7,14 , and 30 days (Figure 2). In general, the group 3 tended to show less inflammatory infiltrate and pulp disorganization compared to calcium hydroxide alone (median score of 1 and 2, respectively), but the difference was not statistically significant $(P>.05)$ (Tables 1 and 2$)$. The BPB-only 

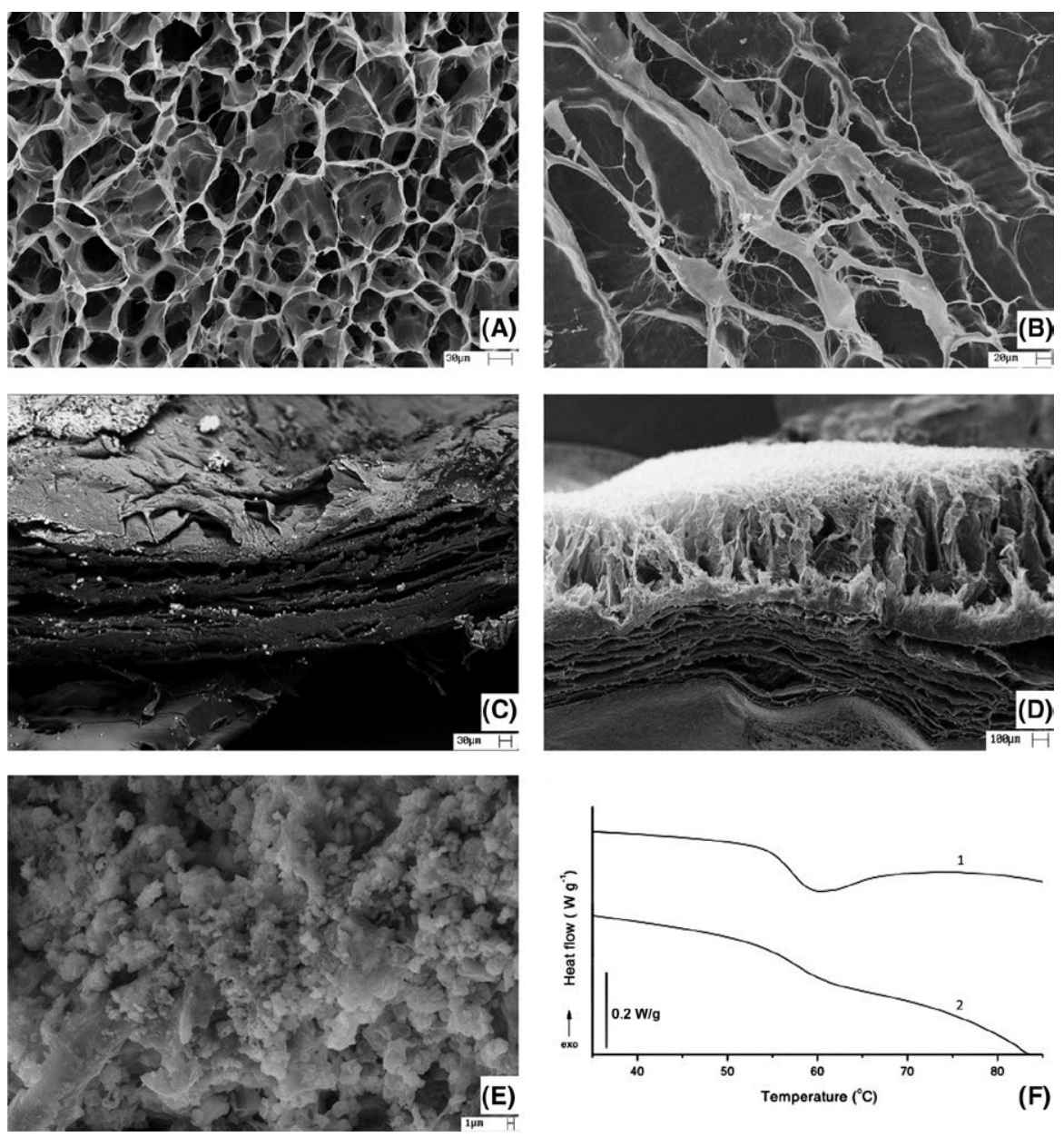

\begin{tabular}{|c|c|c|c|c|c|c|c|c|}
\hline \multirow[b]{2}{*}{ Period (d) } & \multirow[b]{2}{*}{ Groups } & \multirow[b]{2}{*}{$\mathbf{N}$} & \multicolumn{3}{|c|}{ Scores } & \multirow[b]{2}{*}{4} & \multirow[b]{2}{*}{ Median } & \multirow{2}{*}{$\begin{array}{l}\text { Kruskal-Wallis } \\
\text { P-value }\end{array}$} \\
\hline & & & 1 & 2 & 3 & & & \\
\hline \multirow[t]{3}{*}{7} & 1 & 5 & 1 & 3 & 1 & 0 & $2^{\mathrm{a}}$ & \multirow[t]{3}{*}{.018} \\
\hline & 2 & 5 & 0 & 1 & 2 & 2 & $3^{b}$ & \\
\hline & 3 & 5 & 3 & 2 & 0 & 0 & $1^{\mathrm{a}}$ & \\
\hline \multirow[t]{3}{*}{14} & 1 & 5 & 2 & 3 & 0 & 0 & $2^{\mathrm{a}}$ & \multirow[t]{3}{*}{.004} \\
\hline & 2 & 5 & 0 & 0 & 4 & 1 & $3^{b}$ & \\
\hline & 3 & 5 & 1 & 4 & 0 & 0 & $2^{a}$ & \\
\hline \multirow[t]{3}{*}{30} & 1 & 5 & 3 & 2 & 0 & 0 & $1^{\mathrm{a}}$ & \multirow[t]{3}{*}{.006} \\
\hline & 2 & 5 & 0 & 0 & 1 & 4 & $4^{b}$ & \\
\hline & 3 & 5 & 3 & 2 & 0 & 0 & $1^{\mathrm{a}}$ & \\
\hline
\end{tabular}

Group 1, calcium hydroxide alone; group 2, bovine pericardium biomembrane alone; group 3, calcium hydroxide-coated bovine pericardium biomembrane. Intergroup difference was statistically significant at all time points (Kruskal-Wallis one-way analysis of variance). Pairwise multiple comparisons using the Student-Newman-Keuls method revealed the difference to be statistically significant when group 2 was compared to groups 1 and 3, but no difference was found between groups 1 and 3. Same lowercase letters do not indicate statistical differences.

group (group 2), however, showed loss of general pulp tissue morphology, disorganization, and greater inflammatory cell infiltration at all three observation periods at 7, 14, and 30 days (Figure 2) (Tables 1 and 2). There was no evidence of reparative dentine formation observed in any of the experimental groups.
F I G U R E 1 Scanning electron microscopy images describing the microstructure of the matrices. (A) Surface of the matrix on the bovine pericardium side after alkaline hydrolysis revealing a compact structure with the presence of fibers $\times 500$. (B) Surface on the chitosan side, over the bovine pericardium, revealing a formation of a porous matrix $\times 300$. (C) Cross-section of the matrix revealing a spongy side with inter connected channels and the layers that make up the bovine pericardium $\times 500$.

(D) Addition of the gelatin gel containing calcium hydroxide on the chitosan sponge. (E) Calcium hydroxide adhered to the matrix. (F) Result of differential scanning calorimetry curves obtained in dynamic $\mathrm{N}_{2}$ atmosphere $\left(50 \mathrm{~mL} \mathrm{~m}^{-1}\right)$ and heating rate $10 \mathrm{C} \mathrm{m}^{-1}$. Curve 1 , bovine pericardium biomembrane; curve 2, bovine pericardium biomembrane + calcium hydroxide

TA B L E 1 Summary of pulp tissue disorganization after pulp capping with the test materials analyzed at 7,14 , and $30 \mathrm{~d}$

\section{4 | DIsCUSSION}

Pulp capping is a conservative procedure aimed at preserving pulp vitality, and is important for avoidance of root canal treatment and the devitalization of teeth. Although calcium hydroxide has 
TA B L E 2 Summary of inflammatory cell infiltration results after pulp capping with the test materials analyzed at 7, 14, and $30 \mathrm{~d}$

F I G U R E 2 Representative images of hematoxylin-eosin staining showing histological changes in the dental pulp of the three experimental groups at 30 days. Control group of calcium hydroxide capping without biomembrane.

(A) Incipient fibrosis and angiogenesis;

(B) mild acute/chronic cell lesion; (C) calcium hydroxide-coated bovine pericardium biomembrane group showing the presence of fibrosis and discrete angiogenesis (revascularizing); (D) Few scattered inflammatory cells in the pulp. (E) Bovine pericardium biomembranealone group showing the presence of moderate fibrosis, acute inflammation, and discrete angiogenesis; (F) necrosis in the coronal third or more of the pulp

\begin{tabular}{|c|c|c|c|c|c|c|c|c|}
\hline \multirow[b]{2}{*}{ Period (d) } & \multirow[b]{2}{*}{ Group } & \multirow[b]{2}{*}{$\mathbf{N}$} & \multicolumn{5}{|c|}{ Scores } & \multirow{2}{*}{$\begin{array}{l}\text { Kruskal-Wallis } \\
P \text {-value }\end{array}$} \\
\hline & & & 1 & 2 & 3 & 4 & Median & \\
\hline \multirow[t]{3}{*}{7} & 1 & 5 & 1 & 4 & 0 & 0 & $2^{\mathrm{a}}$ & \multirow[t]{3}{*}{.004} \\
\hline & 2 & 5 & 0 & 0 & 3 & 2 & $3^{b}$ & \\
\hline & 3 & 5 & 3 & 2 & 0 & 0 & $1^{\mathrm{a}}$ & \\
\hline \multirow[t]{3}{*}{14} & 1 & 5 & 0 & 5 & 0 & 0 & $2^{\mathrm{a}}$ & \multirow[t]{3}{*}{.002} \\
\hline & 2 & 5 & 0 & 0 & 2 & 3 & $4^{b}$ & \\
\hline & 3 & 5 & 1 & 4 & 0 & 0 & $2^{\mathrm{a}}$ & \\
\hline \multirow[t]{3}{*}{30} & 1 & 5 & 1 & 4 & 0 & 0 & $2^{\mathrm{a}}$ & \multirow[t]{3}{*}{.003} \\
\hline & 2 & 5 & 0 & 0 & 1 & 4 & $4^{b}$ & \\
\hline & 3 & 5 & 4 & 1 & 0 & 0 & $1^{\mathrm{a}}$ & \\
\hline
\end{tabular}

Group 1, calcium hydroxide alone; group 2, bovine pericardium biomembrane alone; group 3: calcium hydroxide-coated bovine pericardium biomembrane. Intergroup difference was statistically significant at all time points (Kruskal-Wallis one-way analysis of variance). Pairwise multiple comparisons using the Student-Newman-Keuls method revealed the difference to be statistically significant when group 2 was compared to groups 1 and 3, but no difference was found between groups 1 and 3. Same lowercase letters do not indicate statistical differences.
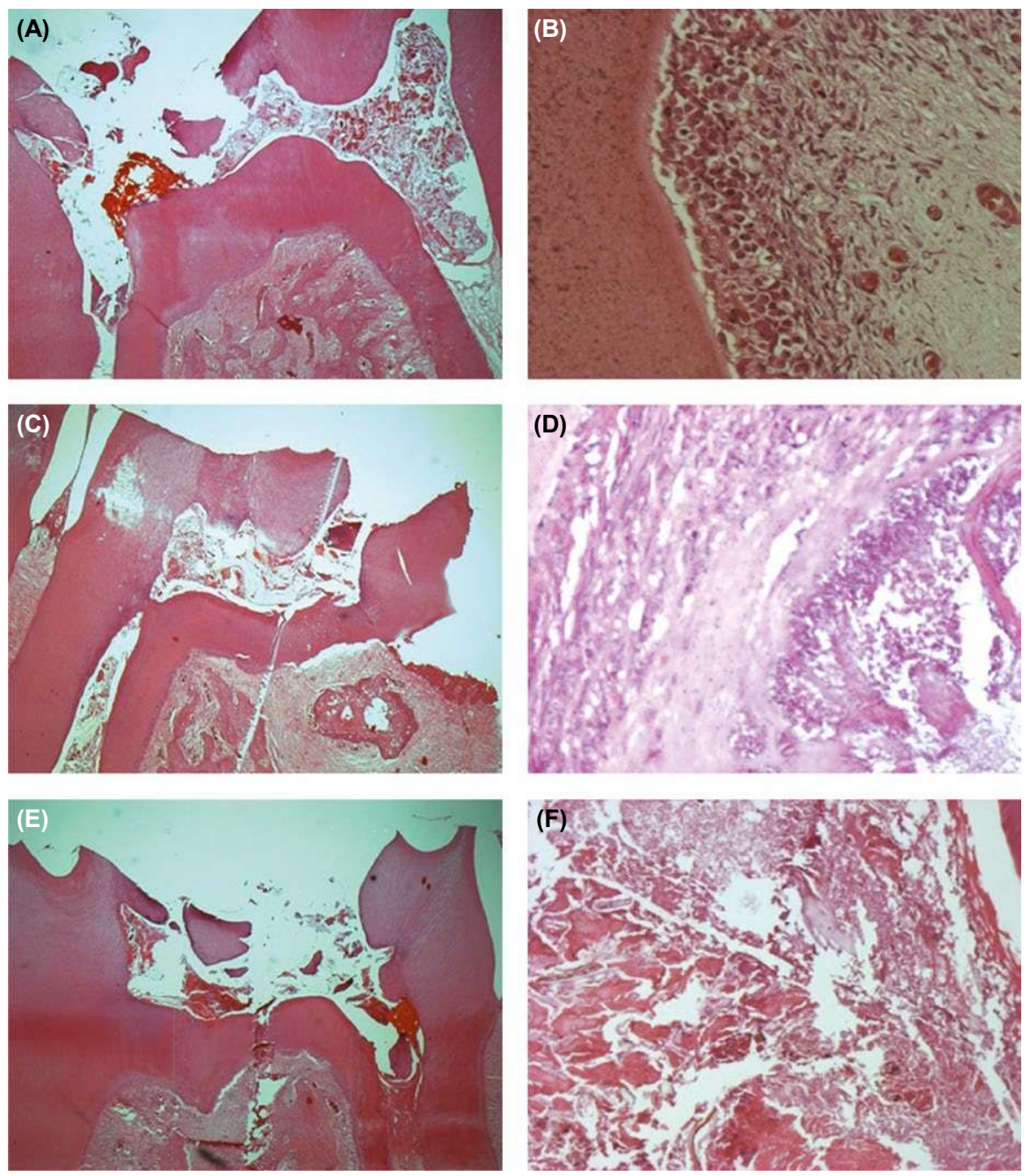

been used to successfully induce reparative dentine formation, the clinical outcomes for this procedure are compromised by the lack of adequate seal and poor mechanical properties of calcium hydroxide. Therefore, strategies to overcome these limitations to enhance calcium hydroxide-based pulp capping outcomes are needed. 
Tissue engineering studies have shown that biomembranes are fully compatible with connective tissue cells, and that such mate- rials are suitable for regenerative and healing processes. ${ }^{16,17}$ In this respect, it has been suggested that materials to be placed in direct contact with pulp tissue, such as growth factors, should be applied to matrices (scaffolds) that provide mechanical support and allow tis- sue development. ${ }^{18,19}$ The results of the present study demonstrate the utility of such an approach. We showed that in pulps treated with calcium hydroxide-coated BPB, there was mild odontoblast layer disorganization and mild inflammatory infiltrate, along with normal pulp tissue appearance. This was expected because calcium hydroxide is a biocompatible material capable of stimulating pulp repair, ${ }^{20,21}$ and the scaffold of biomembranes containing calcium hydroxide might have prevented the diffusion of monomers from adhesives and composite resin to the pulp, which is a very relevant fact from a biologic standpoint. As an advantage, the matrices produced in the present study showed greater thickness and porosity, which facilitated its compaction at the pulp exposure site. Furthermore, the DSC results, shown in Figure $1 F$, revealed that the addition of calcium to the BPB was likely to increase the biomembrane degradation rate, and this is clinically advantageous, as it is preferable that the biomembrane degrades in a timely manner to be replaced by the regenerating pulp/ dentine complex tissue.

In dental pulps capped with the BPB and calcium hydroxide, when tissue disorganization was assessed, there was a predominance of normal or almost normal pulp tissue morphology and two cases of mild cellular disorganization at both 7 and 30 days, postoperatively. At 14 days, there was a predominance of mild disorganization of the surface layer and one case of normal pulp tissue morphology. These features are advantageous with respect to protecting the pulp tissue and preventing reinfection when a conservative approach is used. Despite the predominance of normal pulp tissue appearance in teeth treated with BPB and calcium hydroxide, hard tissue barrier formation was not observed. This was also the case in group 1 , where the pulps were capped with calcium hydroxide alone. Although calcium hydroxide has been previously shown to induce dentine formation by day 28 in some studies, this was not the case in the present study, and it is likely that differences in treatment protocols might account for these discrepancies.

The results of the study showed that BPB without calcium hydroxide had the worst outcome in pulp response. It should be noted that BPB alone has no ability to induce tissue regeneration. Therefore, the presence of calcium hydroxide might not only count for the direct tissue reparative effect but also for anti-inflammatory and antibacterial effects that might have contributed to the biocompatibility of the calcium hydroxide-coated BPB.

Although the results of the present study demonstrated that the use of calcium hydroxide-coated BPB might help maintain a healthy pulp tissue architecture, more work needs to be carried out before these scaffolds can be used in clinical practice. For instance, the degradation of these matrices and their replacement with pulp tissue in vivo using longer time points and validated operative procedures is required. Also, the mechanisms of action of these biomaterials remain to be elucidated, and the application protocols for these biomembranes need to be improved before they can be safely explored in clinical practice.

We also highlight that the animal model of bovine pericardium is well known and widely cited in the literature. ${ }^{11,12}$ Nevertheless, it is up to the researchers to evaluate the risks and/or benefits of the use of this technique when applied in human tissues, considering that the replacement of the pulp loss needs to be extremely superior to the risks.

\section{1 | Conclusion}

In the present study, we successfully developed and characterized the bovine pericardium-based biomembrane and applied it on pulp exposure. The bovine pericardium-based biomembrane coated with calcium hydroxide resulted in favorable outcomes in the case of pulp exposure after a 30-day observation period. The biomembrane scaffold coated with calcium hydroxide could protect pulp injury caused by adhesive systems and composites, as we did not detect necrosis areas in pulps.

\section{R EFER EN CE $S$}

1. Modena KC, Casas-Apayco LC, Atta MT, et al. Cytotoxicity and biocompatibility of direct and indirect pulp capping materials. J Appl Oral Sci. 2009; 17:544-554.

2. Sangwan P, Sangwan A, Duhan J, et al. Tertiary dentinogenesis with calcium hydroxide: a review of proposed mechanisms. Int Endod J. 2013;46:3-19.

3. Chen L, Zheng L, Jiang J, et al. Calcium hydroxide-induced proliferation, migration, osteogenic differentiation, and mineralization via the mitogen-activated protein kinase pathway in human dental pulp stem cells. J Endod. 2016;42:1355-1361.

4. Graham L, Cooper PR, Cassidy N, et al. The effect of calcium hydroxide on solubilisation of bio-active dentine matrix components. Biomaterials. 2006;27:2865-2873.

5. Li Z, Cao L, Fan M, et al. Direct pulp capping with calcium hy-droxide or mineral trioxide aggregate: a meta-analysis. I Endod. 2015;41:1412-1417.

6. Guven Y, Tuna EB, Dincol ME, Ozel E, YImaz B, Aktoren O. Longterm fracture resistence of simulated immature teeth with var- ious calcium silicate based materials. Biomed Res. 2016;2016:1-6. https://www.hindawi.com/journals/bmri/2016/2863817/

7. De Deus G, Ferreira CB, Oliveira S, et al. Resistance of hydraulic calcium silicate cements to dislodgment in short and long term assessment. J Adhes Dent. 2016;18:157-160.

8. Camilleri J, Sorrentino F, Damidot D. Investigation of the hydration and bioactivity of radiopacified tricalcium silicate cement. Biodentine and MTA Angelus. Dent Mater. 2013;29:580-593.

9. Schembri Wismayer P, Lung CY, Rappa F, et al. Assessment of the interaction of Portland cement-based materials with blood and tissue fluids using an animal model. Sci Rep. 2016;29:1-9.

10. Li F, Liu X, Zhao S, et al. Porous chitosan bilayer membrane containing TGF- $\beta 1$ loaded microspheres for pulp capping and reparative dentin formation in a dog model. Dent Mater. 2014;30:172-181. 
11. Lee WK, Park KD, Han DK, et al. Heparinized bovine pericar- dium as a novel cardiovascular bioprosthesis. Biomaterials. 2000;21:23232330.

12. Forti FL, Goissis G, Plepis AM. Modifications on collagen structures promoted by 1,4-dioxane improve thermal and biological properties of bovine pericardium as a biomaterial. JBiomater Appl. 2006;20:267-285.

13. Bet MR, Goissis G, Lacerda CA. Characterization of polyanionic collagen prepared by selective hydrolysis of asparagine and glutamine carboxyamide side chains. Biomacromol. 2001;2:1074-1079.

14. Horn MM, Martins VCA, Plepis AMG. Interaction of anionic collagen with chitosan: effect on thermal and morphological characteristics. Carbohydr Polym. 2009;77:239-243.

15. Medina VO 3rd, Shinkai K, Shirono M, et al. Histopathologic study on pulp response to single-bottle and self-etching adhesive systems. Oper Dent. 2002;27:330-342.

16. Burg KJ, Porter S, Kellam JF. Biomaterial developments for bone tissue engineering. Biomaterials. 2000;21:2347-2359.

17. Goldberg M, Smith AJ. Cells and extracellular matrices of dentin and pulp: a biological basis for repair and tissue engineering. Crit Rev Oral Biol Med. 2004;15:13-27.
18. Tziafas D, Smith AJ, Lesot H. Designing new treatment strategies in vital pulp therapy. J Dent. 2000;28:77-92.

19. Lovschall H, Fejerskov O, Flyvbjerg A. Pulp-capping with recombinant human insulin-like growth factor I (rhIGF-I) in rat molars. Adv Dent Res. 2001;15:108-112.

20. Fava LR, Saunders WP. Calcium hydroxide pastes: classification and clinical indications. Int Endod J. 1999;32:257-282.

21. Holland R, de Souza V, Nery MJ, et al. Reaction of rat connec- tive tissue to implanted dentin tube filled with mineral trioxide aggregate, Portland cement or calcium hydroxide. Braz Dent $J$. 2001;12:3-8.

How to cite this article: Klein-Júnior CA, Reston $\mathrm{E}$, Plepis $A M$, et al. Development and evaluation of calcium hydroxidecoated, pericardium-based biomembranes for direct pulp capping. J Invest Clin Dent. 2018;e12380. https://doi. org/10.1111/jicd.12380 